\title{
(t)
}

\section{EQUIDADE DE GÊNERO E WELFARE STATE PÓS- INDUSTRIAL: A CONTRIBUIÇÃO DE NANCY FRASER}

\author{
GENDER EQUITY AND WELFARE STATE POST-INDUSTRIAL: \\ THE CONTRIBUTION OF NANCY FRASER
}

\section{Alex Myller Duarte Lima' Lúcia Cristina dos Santos Rosa²}

\section{RESUMO}

O presente artigo pretende discutir os possíveis modelos de welfare state pós-industrial sob a ótica feminista, avaliando-os segundo a capacidade que detenham para realizar a equidade de gênero nos termos em que esta é pensada pela filósofa norte-americana Nancy Fraser. Nesse sentido, nem o modelo chamado de provedor universal nem aquele denominado paridade do cuidador - que em termos gerais são defendidos pelas diversas correntes do feminismo - parecem capazes de efetivar as radicais propostas igualitaristas do feminismo. Daí a solução de Fraser, que ela chama de modelo do cuidador universal. Assim, sob a luz da concepção de justiça fraseriana, são criticadas visões reducionistas que pretendem restringir a justiça social a uma de suas dimensões, seja econômica, seja cultural.

Palavras-chave: Equidade. Gênero. Welfare. Justiça.

1 Doutorando do Programa de Pós-Graduação em Políticas Públicas da Universidade Federal do Piauí (UFPI). Mestre em Ética e Epistemologia (UFPI). Especialista em Gestão Fiscal pela Faculdade Michelângelo-DF. Bacharel em Direito (UFPI). E-mail: alexmyller@gmail.com.

2 Pós-doutora em Saúde Coletiva pela Universidade Estadual de Campinas (UNICAMP). Doutora em Sociologia pela Universidade Federal de Pernambuco (2000). Doutora em Serviço Social pela Universidade Federal do Rio de Janeiro (2000). Mestre em Serviço Social pela Universidade Federal de Pernambuco (1994). Atualmente é Professora Associada III da Universidade Federal do Piauí. E-mail: luciacsrosa@gmail.com. 


\section{temporalis}

\section{ABSTRACT}

This article discusses the possible models of post-industrial Welfare State under the feminist perspective, evaluating them according to ability to achieve gender equity as it is conceived by American philosopher Nancy Fraser. In this sense, neither the universal breadwinner model nor the caregiver parity model - which generally are upheld by the various currents of feminism - seem able to actualize the radical egalitarian proposals of feminism. Hence Fraser's solution, which she calls the universal caregiver model. Thus, in light of the fraserian conception of justice, we criticize views that reduce social justice to one of its dimensions, either economical or cultural.

Keywords: Equity. Gender. Welfare. Justice.

Submetido em 31/03/2014

Aceito em 17/09/2014

\section{INTRODUÇÃO}

Um traço destacado das lutas sociais em fins do século XX e início do século XXI tem sido o fortalecimento de movimentos sociais comprometidos com a defesa de grupos historicamente injustiçados tanto economicamente quanto de um ponto de vista cultural ou simbólico - movimento feminista, movimento negro, movimento de gays e lésbicas, entre muitos outros. Não que tais iniciativas inexistissem no período anterior, porém, com a derrocada do socialismo soviético, tenderam a assumir cada vez mais a bandeira da luta pelo reconhecimento da diferença como projeto autônomo de ação social, muitas vezes secundarizando ou eclipsando a velha problemática da desigualdade econômica.

Essa reviravolta nas demandas por justiça social vem ocorrendo, porém, no contexto de um mundo ainda profundamente desigual em termos econômicos (UNITED NATIONS, 2003, 2005), exigindo então que as duas espécies de demandas por justiça sejam entrosadas de forma harmônica, sem o solapamento de quaisquer dessas dimensões. A necessidade de entrosamento das políticas de redistribuição econômica e de reconhecimento cultural parece ainda mais relevante se considerarmos que 0 welfare state há décadas atravessa uma crise mundial de muitas raízes, desde as tendências econômicas globais à ascensão de antagonismos étnico-"raciais" e nacionais, passando pelo 
enfraquecimento dos sindicatos/partidos laborais e pelo colapso do socialismo estatal (FRASER, 1994, 1997).

Fraser alerta para a dificuldade de harmonização dos dois tipos de políticas requeridas - de redistribuição e de reconhecimento -, apontando inclusive discrepâncias teóricas quanto ao tema:

\begin{abstract}
Crescentemente, [...] redistribuição e reconhecimento são retratados como alternativas mutuamente excludentes. Alguns proponentes da primeira, tais como Richard Rorty, Brian Barry, e Todd Gitlin, insistem que a política de identidade é um desvio contraprodutivo das questões econômicas reais [...]. Contrariamente, alguns proponentes do reconhecimento, tal como Iris Marion Young, insistem que uma política de redistribuição cega-às-diferenças pode reforçar a injustiça ao universalizar falsamente normas do grupo dominante, requerendo que grupos subordinados as assimilem, e não reconhecendo a peculiaridade dos últimos (FRASER; HONNETH, 2003, p. 15).
\end{abstract}

Especificamente quanto às questões de gênero, "tendências ativistas que olham para a redistribuição como o remédio para a dominação masculina estão crescentemente dissociadas das tendências que olham ao invés para o reconhecimento da diferença de gênero" (FRASER; HONNETH, 2003, p. 8). São claras a intensificação e a bifurcação desse debate dentro do movimento feminista internacional, no qual "para um grupo [...] a essência do feminismo é uma crítica da dominação sexual" e "para o outro grupo [...] a essência do feminismo é uma crítica da dependência econômica das mulheres" (NUSSBAUM, 2000, p. 290).

O tema da justiça de gênero é relevante para as discussões sobre o welfare state porque a derrocada da antiga ordem de gênero é, a um só tempo, fator crucial para a crise do regime de bem-estar acima referida (FRASER, 1994) e urgente desafio para essa forma de organização social no albor do século XXI (PALIER, 2010; ESPING-ANDERSEN, 2010).

O presente artigo, dessa forma, busca analisar os diferentes cenários imagináveis para a efetivação de um welfare state 


\section{temporalis}

pós-industrial igualitário em termos de gênero - ou seja, trata-se aqui de um "experimento mental pós-industrial" (FRASER, 1997, p. 41). Para tanto, tem-se em conta a noção complexa de equidade de gênero formulada por Nancy Fraser, que servirá de guia as avaliações e ponderações das opções de welfare, em conformidade com o espírito não reducionista da reflexão fraseriana.

\section{SALÁRIO FAMÍLIA E CRISE DA ORDEM DE GÊNERO}

O contexto dessa polarização das forças sociais progressistas (movimentos de trabalhadores, feminista, negro, LGBT nos EUA, por exemplo, divididos em Esquerda Social e Esquerda Cultural) é também o da crise do estado de bem-estar, ou seja, da provisão de serviços sociais, cobrindo as mais variadas formas de risco da vida individual e coletiva enquanto direito assegurado pelo Estado à maioria da população dos países capitalistas centrais (ARRETCHE, 1995). Tal regime foi antes bem-sucedido (apesar dos graus variáveis desse sucesso) em harmonizar crescimento econômico e elevação dos patamares de vida da população, em especial na Europa. De fato, o crescimento econômico do pós-guerras, nos chamados "Trinta Gloriosos", "repousa em grande parte nas benéficas interações entre o desenvolvimento de uma indústria de bens padronizados, de grande consumo, o consumo de massa e a generalização da proteção social" (PALIER, 2010, p. 8-9).

Contudo, mudanças econômicas e sociais alteraram a face das sociedades industriais em fins do século XX e as políticas sociais construídas após a Segunda Guerra Mundial parecem cada vez mais desajustadas econômica e socialmente. A abertura progressiva das economias, a globalização das trocas comerciais e a circulação dos capitais promoveram o deslocamento das atividades econômicas, em especial para o Leste (europeu e, sobretudo, asiático) daquelas atividades industriais de massa que exigem mão de obra pouco custosa e pouco qualificada. Países antigamente industrializados se voltam a novas atividades pós-industriais, baseadas na inovação tecnológica, nas altas qualificações, no conhecimento, bem como aos serviços (qualificados ou não), especialmente os serviços à pessoa. 
Bruno Palier (2010) explica que os sistemas de proteção alicerçados em seguros sociais, concebidos originariamente para proteger os trabalhadores industriais de baixa qualificação e contrato de duração indefinida, mostram-se atualmente mal adaptados para o contexto de vidas laborais mais móveis e caóticas, quase sempre mais precárias, típicas da nova economia. Além disso, as políticas sociais deixaram de ser apresentadas como uma forma de apoiar a economia e seu modo de financiamento passou a ser encarado como um custo diante da concorrência fiscal entre os Estados.

Porém, a mudança social mais importante das últimas décadas é justamente a entrada massiva da mulher no mercado de trabalho, algo que perturba o funcionamento de sistemas de proteção social concebidos sob um modelo familiarista, no qual os direitos são concedidos àquele (raramente àquela) que possui uma atividade remunerada e por extensão aos membros de sua família (PALIER, 2010). Esping-Andersen acerta ao lembrar que o debate sobre o futuro do welfare state, centrado nas ameaças da globalização e do envelhecimento, "tem ignorado de forma sistemática uma força de mudança seguramente mais revolucionária: a mudança do papel das mulheres na sociedade" (ESPINGANDERSEN, 2010, p. 19), refletida na modificação das trajetórias vitais femininas.

Logo, a ordem de gênero que está desaparecendo em nossa época descende da era industrial do capitalismo e reflete o mundo social em que teve origem, centrado no ideal do salário-família (family wage), que pressupunha a organização das pessoas em famílias nucleares heterossexuais dirigidas por um homem, ao qual seria paga uma remuneração suficiente para sustentar filhos e uma esposa-e-mãe em tempo integral, que realizaria trabalho doméstico não pago. Apesar de inúmeras vidas não se ajustarem a esse modelo, ele ainda assim serviu e tem servido como referencial normativo da família (FRASER, 1997). Nessa perspectiva, Rosa (2014) aponta que essas associações são antigas no imaginário ocidental cristão.

De fato, "Lorde Beveridge e outros construtores do Estado de bem-estar do pós-guerra assumiram explicitamente que as 


\section{temporalis}

mães seriam donas-de-casa" (ESPING-ANDERSEN, 1999, p. 54). Assim, o ideal do salário-família estava inscrito na estrutura da maior parte dos welfare states da era industrial (FRASER, 1994).

A crise desses regimes de bem-estar liga-se, portanto, à fase pós-industrial do capitalismo e está enraizada em parte no colapso do mundo do salário-família. Atualmente, poucos empregos pagam salários suficientes para a manutenção de uma família - muitos são na verdade trabalhos temporários ou de tempo parcial que não gozam do mesmo padrão de benefícios daqueles de tempo integral. Também já foi mencionado o acréscimo de mulheres no trabalho assalariado, quase sempre com salários consideravelmente mais baixos que os dos homens e frequentemente em ocupações informais e precárias. Ao mesmo tempo, as famílias pós-industriais são também menos convencionais e mais diversas: heterossexuais se casam menos e mais tardiamente e se divorciam mais cedo e com mais frequência; gays e lésbicas constroem novos tipos de desenhos domésticos - em suma, as normas de gênero e as formas familiares são altamente pluralizadas. Hoje, portanto, o pressuposto do salário-família não é mais sustentável, empírica ou normativamente (FRASER, 1994).

Nesse novo contexto parece claro que ainda será necessário algum tipo de welfare state pós-industrial - não tanto uma modificação ou adaptação de sistemas surgidos do passado, mas uma formulação de novos princípios e novas pistas (FRASER, 1997; PALIER, 2010). Obviamente, assim como seu antecessor, ele se apoiará numa ordenação da questão do gênero - com o alerta de que a única espécie de ordem de gênero aceitável hoje é precisamente uma que tenha como premissa a equidade.

Segundo Fraser (1994), as feministas estão em uma posição vantajosa para a geração de uma visão emancipatória do período vindouro, pois, mais do que quaisquer outros, seus estudos destacam a importância das relações de gênero para a crise do welfare state industrial e a centralidade da equidade nesse campo para qualquer alternativa viável. Contudo, as feministas não têm se arriscado ao pensamento reconstrutivo sistemático acerca do welfare state nem desenvolveram ainda uma explicação 
satisfatória da equidade de gênero que pudesse informar aquela visão emancipatória.

\section{EQUIDADE DE GÊNERO COMPLEXA}

O tema "gênero" é abordado por Fraser no contexto dos dilemas enfrentados pelas teorias contemporâneas de justiça. Ele possui uma dimensão político-econômica inarredável, constituindo um princípio estruturador básico na economia política: por um lado, estrutura a divisão entre trabalho produtivo pago e trabalho reprodutivo e doméstico não pago; por outro, a divisão dentro do trabalho pago entre ocupações mais bem remuneradas e profissionais, dominadas pelos homens, e ocupações mal remuneradas e voltadas para serviços domésticos, dominadas pelas mulheres. Mas "gênero" também é uma diferenciação cultural-valorativa. Nesse campo, permanece a construção de normas que privilegiam traços associados com a masculinidade (androcentrismo) e a desvalorização de coisas codificadas como "femininas" (sexismo cultural). Essa inferiorização se expressa nos diversos danos sofridos pelas mulheres, entre eles o assédio sexual, a exploração sexual, a violência doméstica, a marginalização na esfera pública e nos corpos deliberativos, além das estereotípicas representações midiáticas trivializantes, humilhantes e objetificantes da mulher.

Em resumo, conforme Fraser (1995), "gênero" é justamente uma coletividade ambivalente ou categoria social bidimensional que requer tanto redistribuição quanto reconhecimento para remediar a injustiça que os seus indivíduos-componentes sofrem cotidianamente. A solução adotada por Fraser, nesse passo, é tratar a justiça como bidimensional. Tal visão enfrentará redistribuição e reconhecimento como perspectivas ou dimensões distintas da justiça, sem reduzir uma a outra, abrangendo-as dentro de um arcabouço mais amplo (FRASER, 2001; FRASER; HONNETH, 2003).

Já foi dito que o pensamento feminista raramente se deteve na formulação de uma reconstrução sistemática do welfare state, isto é, em responder a nova ordem de gênero, que deveria substituir o velho salário-família ou que tipo de estado de bem-estar poderia sustentar melhor essa nova ordem de gênero. A resposta da primeira questão necessariamente teria por suposto 


\section{temporalis}

um critério normativo que orientaria a resolução da segunda. Por esse motivo, Fraser dedica-se inicialmente a clarificar alguns dilemas que circundam "igualdade" e "diferença” por meio da reconstrução do que significa equidade de gênero.

Entre as próprias feministas, essa equidade tem sido associada tanto à exigência de um tratamento exatamente igual para homens e mulheres (igualdade) quanto ao tratamento diferenciado das mulheres na medida em que elas se diferenciam dos homens (diferença), além obviamente dos diversos grupos dentro das próprias mulheres e que se constituem por questões de "raça"/etnia, geração, orientação sexual etc. Muitas vezes, os méritos relativos dessas abordagens são debatidos como se representassem dois polos antitéticos de uma dicotomia absoluta, em que os respectivos argumentos levam a becos sem saída:

Proponentes da "diferença" têm exitosamente mostrado que estratégias de igualdade tipicamente pressupõem "o masculino como norma", desfavorecendo dessa forma as mulheres e impondo um padrão distorcido sobre todos. Igualitaristas têm argumentado também convincentemente, entretanto, que as abordagens da diferença tipicamente apoiam-se em noções essencialistas de feminilidade, reforçando assim estereótipos existentes e confinando as mulheres dentro das divisões de gênero existentes (FRASER, 1994, p. 44).

A proposta de Fraser é afastar a assunção de que a equidade de gênero possa ser identificada com uma única norma ou valor, reconceituando-a como uma ideia complexa (por oposição a simples), como uma noção compreendendo vários princípios normativos distintos relativos a cada um dos lados do debate "igualdade versus diferença" e ainda outros critérios aos quais nenhum dos polos atribuiu o peso devido. Mas o ponto fulcral seria a exigência de que as várias normas distintas devem ser respeitadas simultaneamente para que a equidade seja atingida. Para avaliar a questão do welfare, a filósofa indica a equidade de gênero como um composto de sete princípios normativos distintos, a saber (FRASER, 1994): 
a) Princípio antipobreza. A prevenção da pobreza, além de primeiro e mais óbvio objetivo da provisão do bem-estar social, é crucial para a equidade de gênero atualmente, após a era do salário-família. Com efeito, predominam hoje as altas taxas de pobreza entre as famílias de mães-solteiras e monoparentais de chefial responsabilidade feminina em geral, bem como é consideravelmente aumentada a possibilidade de que mulheres e crianças vivam em tais arranjos domésticos. Contudo, nem todas as formas de satisfação desse princípio serão aceitáveis: benefícios estigmatizantes e isolantes para o alívio das famílias de mães-solteiras não preencherão os requisitos normativos a seguir especificados.

b) Princípio antiexploração. Combater a pobreza é importante também como um meio de evitar a exploração de pessoas vulneráveis. Com efeito, mulheres necessitadas sem algum meio para alimentar a si mesmas e a seus filhos são vítimas fáceis de maridos abusivos, chefes de empresas com trabalho degradante e cafetões. A disponibilização de uma fonte alternativa de renda eleva a posição de barganha dos subordinados em relações assimétricas - mas esse apoio deve ser concedido como uma questão de direito, pois o princípio não é cumprido se o recebimento de auxílio é altamente estigmatizado ou discricionário. O objetivo seria evitar a dependência explorável em relação a um membro individual da família (marido, criança adulta), a empregadores e supervisores ou mesmo a caprichos pessoais de agentes estatais. Nesse sentido, estão proscritos arranjos que canalizem os benefícios a uma dona de casa através de seu marido ou ainda os que condicionem o acesso a bens essenciais, como os cuidados com a saúde, a empregos escassos.

c) Princípio da igualdade de renda. Também crucial para a equidade de gênero é a igualdade de renda entre homens e mulheres. Afinal, os ganhos destas giram em torno de $70 \%$ dos ganhos masculinos. Muito do trabalho feminino não é compensado de nenhuma forma e muitas mulheres sofrem de pobreza oculta em razão da repartição desigual no interior das famílias. Assim, o princípio exige a abolição do pagamento desigual por trabaIho igual e da subvalorização do trabalho e das habilidades das mulheres, ou seja, a redução da vasta discrepância entre as rendas dos homens e das mulheres. 


\section{temporalis}

d) Princípio da igualdade do tempo de lazer. Após a era do salário-família, a questão da distribuição do tempo de lazer torna-se premente, pois muitas mulheres (mas poucos homens) efetuam tanto o trabalho pago quanto o cuidado primário não pago e passam a sofrer então de pobreza de tempo. O princípio exclui os arranjos de bem-estar que equalizariam as rendas e simultaneamente exigiriam das mulheres (mas não dos homens) uma dupla jornada de trabalho. Também banidos seriam os arranjos que demandassem apenas das mulheres o trabalho da reivindicação ou a absorvente tarefa de juntar as parcelas de renda de várias fontes e de coordenar os serviços de diferentes agências e associações.

e) Princípio da igualdade de respeito. O tipo de igualdade propugnada por esse normativo é urgente na atualidade, quando a cultura pós-industrial rotineiramente representa as mulheres como objetos para o prazer dos sujeitos masculinos. Segundo esse princípio, estão excluídos quaisquer arranjos que objetifiquem e depreciem as mulheres - ainda que eles previnam a pobreza e a exploração e mesmo que simultaneamente garantam a igualdade de renda e de tempo para o lazer. Portanto, suas exigências são incompatíveis com programas de bem-estar que trivializem as atividades das mulheres e ignorem suas contribuições.

f) Princípio antimarginalização. Apesar de cumprir os ditames igualitários acima, um regime de welfare pode mesmo assim marginalizar as mulheres. Fraser (2004, p. 48) explica que "limitando o apoio a pensões maternas generosas, por exemplo, ele poderia tornar as mulheres independentes, bem providas, bem descansadas, e respeitadas, mas insuladas em uma esfera doméstica separada, removida da vida da sociedade mais ampla". Contra esses perigos, a política social deveria promover a participação plena das mulheres em pé de igualdade com os homens em todas as áreas da vida social. Daí a exigência de provisão das condições necessárias à participação feminina - disponibilização do cuidado com idosos e crianças, facilitação da amamentação em público etc. O princípio também requer o desmantelamento das culturas de trabalho machistas e dos ambientes políticos hostis às mulheres.

g) Princípio do antiandrocentrismo. Por fim, mesmo cumprindo as exigências anteriores, um welfare state pode ainda entrincheirar algumas normas de gênero ofensivas - por exemplo, assumindo 
a visão androcêntrica de que os padrões atuais de vida dos homens representam uma regra a ser assimilada pelas mulheres. De fato, as políticas sociais não deveriam exigir das mulheres que estas se tornem tal como os homens, nem que se encaixem em instituições projetadas para homens, como requisitos para o gozo de níveis comparáveis de bem-estar. Ao contrário, teriam por alvo a reestruturação das instituições androcêntricas para que possam dar boas-vindas a seres humanos capazes de dar à luz e que frequentemente cuidam dos parentes e amigos. Isso equivaleria a descentrar as normas machistas, revalorizando práticas e traços correntemente desvalorizados porque se encontram associados às mulheres. Em suma, o antiandrocentrismo exigiria tanto a mudança dos homens quanto das mulheres.

\section{VISÕES DE UMA SOCIEDADE PÓS- INDUSTRIAL E EQUIDADE DE GÊNERO}

Com esse guia normativo, a questão passa a ser então determinar qual a nova ordem de gênero a substituir o salário-família; ou ainda, precisar a que tipo de welfare state ela corresponde. Fraser $(1994,1997)$ pensa que duas respostas são atualmente concebíveis, ambas merecendo a qualificação de feministas - o modelo do Provedor Universal (universal breadwinner) e o modelo da Paridade do Cuidador (caregiver parity).

\section{O MODELO DO PROVEDOR UNIVERSAL}

A pretensão central desse modelo é permitir que as mulheres sustentem a si mesmas e a suas famílias por meio de seus próprios ganhos salariais. Isso significa universalizar o papel de provedor, de modo que as mulheres também possam ser cidadãs-trabalhadoras.

Obviamente se trata de um cenário ambicioso para a era pós-industrial e exige programas e políticas novos e de amplo espectro. Um ponto essencial é a disponibilização de serviços como creches, atendimento a idosos, preparo de refeições (restaurantes populares), liberando as mulheres de tais responsabilidades para permitir que assumam empregos de tempo integral em termos comparáveis aos dos homens. Também é necessário um conjunto de reformas nos locais de trabalho que afastem 


\section{temporalis}

obstáculos como o assédio sexual ou a discriminação pelo sexo. Logicamente, isso requereria mudanças culturais como a eliminação de estereótipos sexistas e a quebra da associação entre prover e masculinidade. Além disso, seriam necessárias políticas que alterassem a socialização, reorientando as aspirações femininas rumo ao emprego/ocupação e as expectativas masculinas no sentido de aceitação do novo papel das mulheres. Mais que tudo, a opção pelo provedor universal somente tem sentido em conjunto com políticas macroeconômicas que criem empregos integrais, permanentes e de remuneração elevada para as mulheres.

Nesse quadro, a maior parte do cuidado/assistência se deslocaria da família para o mercado e o Estado e seria exercida por empregados remunerados por esse serviço. Se considerarmos que a maior parte do cuidado pago institucional é mal remunerado e feminizado, o modelo deve elevar o status e o pagamento associados a empregos assistenciais para evitar um paradoxo. Portanto, o Provedor Universal está necessariamente comprometido com uma política de "valor comparável", devendo remediar a difundida subestimação de habilidades e trabalhos atualmente codificados como femininos, inclusive garantindo-Ihes remunerações que atinjam o nível de provedor.

O modelo usualmente vincularia muitos benefícios à ocupação, distribuindo-os por meio do seguro social segundo os ganhos de cada um. Nesse sentido, lembra a era industrial do welfare state, mas com a diferença de que muito mais mulheres gozariam dessa cobertura com base em seus próprios registros de emprego, os quais pareceriam bem mais que hoje com os dos homens. Para os adultos incapazes de trabalhar, não dispostos ou relutantes a obter empregos - estes últimos geralmente mulheres com responsabilidades assistenciais de difícil transferência -, existiria uma camada residual de bem-estar social composta por rendas substitutivas (FRASER, 1994, 1997).

\section{O MODELO DA PARIDADE DO CUIDADOR}

A pretensão central desse modelo é permitir que as mulheres com responsabilidades domésticas significativas sustentem a si mesmas e a suas famílias por meio do seu trabalho assistencial ou por uma conjunção deste com empregos de tempo parcial. 
Aqui não se trata de fazer a vida das mulheres mais parecida com a dos homens, mas de tornar a diferença sem custos. Para tanto, a gravidez, a criação dos filhos e o trabalho doméstico informal devem ser elevados à paridade com o trabalho formal pago. $\mathrm{O}$ papel de cuidador estaria assim em pé de igualdade com o de provedor.

Assim como no caso anterior, novos programas de largo alcance seriam necessários. Um deles seria o de subsídios a cuidadores, com a finalidade de compensar a gestação, a criação dos filhos, o serviço do lar e outras formas de trabalho doméstico socialmente necessário - benefícios que deveriam ser suficientemente generosos para sustentar uma família (algo equivalente ao salário de um provedor). Indispensáveis as reformas nos locais de trabalho que permitissem a combinação de cuidado subsidiado com empregos de tempo parcial e, ainda, facilitassem as transições entre as diferentes situações vitais. Isso significaria maior flexibilidade: possibilidade de os cuidadores entrarem e saírem dos empregos sem perdas na seguridade, de acomodarem seus horários de trabalho as suas responsabilidades assistenciais ou mesmo de alternarem períodos de trabalho em tempo integral com outros de tempo parcial. Tudo isso em conjunto com um generoso programa de licenças familiares e afastamentos para gravidez.

Assim, a maior parte do cuidado seria mantida no âmbito doméstico, mas apoiado com fundos públicos. O sistema de seguridade também deve ser agudamente diverso do modelo anterior: empregos parciais e trabalho assistencial informal devem gozar da mesma cobertura de ocupações de tempo integral; anos de cuidado subsidiado contariam em pé de igualdade com anos de emprego no que diz respeito à elegibilidade para aposentadorias, seguro-desemprego etc.; além disso, o nível dos benefícios seria fixado de modo a tratar igualmente cuidado e emprego. Da mesma forma que antes, um resíduo de bem-estar social precisaria abranger aquelas pessoas incapazes tanto para o trabalho assalariado quanto para as tarefas assistenciais - a maioria das quais seriam homens, que perceberiam substitutivos de renda e subsídios (FRASER, 1994, 1997). 


\section{temporalis}

\section{PROVEDOR UNIVERSAL VERSUS PARIDADE DO CUIDADOR: UMA COMPARAÇÃO À LUZ DA EQUIDADE DE GÊNERO FRASERIANA}

A própria Fraser $(1994,1997)$ estima a capacidade desses modelos em realizar os princípios normativos da equidade de gênero entendida pluridimensionalmente. É explicitamente assumido que nenhum dos dois modelos existe na prática (profundas mudanças seriam necessárias para tanto), mas o poder heurístico das formulações justifica o experimento mental.

Os dois modelos são bons no combate à pobreza e à exploração. No caso do provedor universal, empregos de qualidade para todas as mulheres e homens empregáveis manteriam a maior parte das famílias fora da pobreza e benefícios residuais generosos fariam o mesmo pelas outras pessoas. Ele também preveniria a dependência explorável da maioria das mulheres, garantindo-lhes opções de saída das relações insatisfatórias com seus parceiros - o que também valeria para o sistema residual de proteção, assumindo seu caráter generoso, não discricionário e honroso. Por sua vez, o modelo de paridade do cuidador, por meio de benefícios suficientemente generosos, manteria as famílias de mães-solteiras (e monoparentais de chefia responsabilidade feminina em geral) fora da pobreza mesmo em períodos de cuidado em tempo integral ou de coexistência de empregos parciais com cuidado financiado parcial. Ainda mais porque cada uma dessas opções carregaria o pacote básico de seguridade social - de fato, mulheres com padrões "femininos" de trabalho gozariam de considerável segurança. Também seria exitoso contra a exploração, vez que provisão direta de renda às esposas não empregadas e às mulheres solteiras (ou viúvas, divorciadas, separadas etc.) com filhos as tornaria menos suscetíveis de exploração pelos maridos ou chefes.

O princípio da igualdade de renda provavelmente seria apenas razoavelmente concretizado num contexto de universalização do papel de provedor. Apesar de os empregos assegurados às mulheres reduzirem a discrepância por gênero nos salários (e certamente também nos benefícios do seguro social) e as opções de saída do casamento encorajarem uma distribuição mais equitativa de recursos em seu interior, o modelo supõe uma linha que 
divide os provedores dos demais, com considerável desvantagem para estes, a maiorias dos quais seriam mulheres. Ademais, não garante a redução das diferenças salariais entre os diversos empregos de provedor, apenas reduzindo o peso do gênero na destinação dos indivíduos a essas ocupações. Na visão de Fraser, o modelo de paridade do cuidador faria ainda menos pela igualdade de renda por gênero (como sabido da experiência Nórdica), vez que o sistema de benefícios associados a salários acaba por criar uma faixa específica no emprego para mães - um mercado de trabalhos parciais e/ou integrais flexíveis e descontínuos (mommy track). Dada a cultura e a socialização atuais, inevitavelmente essas faixas carregarão associações tradicionais baseadas no gênero que provavelmente produzirão discriminação contra as mulheres na faixa/carreira de provedor (FRASER, 1997).

A situação se inverteria quanto ao princípio da igualdade do tempo de lazer. Aqui, o modelo do provedor universal teria um desempenho fraco (como sabido da experiência comunista), pois assumiria de forma irrealista que todas as responsabilidades assistenciais e domésticas que atualmente pesam sobre as mulheres poderiam ser transferidas para o mercado e/ou Estado. Contudo, algumas delas, tais como a criação dos filhos e o atendimento às emergências familiares, dificilmente podem ser completamente deslocadas; outras, apesar da possibilidade, exigiriam uma preparação para a aceitação de arranjos de vivência coletiva. Assim, as chances de lazer igual para as mulheres dependerão da assunção pelos homens de sua justa parcela do "trabalho do cuidado", algo que o modelo não parece estimular - ao contrário, ao valorizar sobremaneira o trabalho remunerado ele implicitamente desvaloriza o não pago. Por outro lado, o modelo da paridade do cuidador parece ser razoável nesse quesito, vez que torna possível para todas as mulheres evitar a dupla jornada se optarem pelo cuidado subsidiado (integral ou parcial) ao longo de suas vidas. A escolha ainda possui algum custo, pois as mulheres que escolherem combinar um emprego da faixa de provedor com o cuidado e que não tenham parceiros cuidadores serão significativamente prejudicadas no que concerne ao tempo para lazer.

Quanto à promoção da igualdade de respeito, ambos os modelos são apenas razoáveis. Nos moldes do Provedor Universal, 


\section{temporalis}

a única chance de eliminar o hiato de respeito por gênero seria a admissão das mulheres ao status de cidadão-trabalhador nos mesmos termos dos homens. No entanto, é mais provável que as mulheres mantenham uma conexão maior que os homens com a reprodução e a domesticidade. Ademais, pela valorização do status de provedor, outros papéis tendem a ser desrespeitados. Com isso, os participantes do sistema residual de proteção - em sua maioria mulheres - estarão suscetíveis à estigmatização social. $\mathrm{Na}$ verdade, qualquer modelo centrado no emprego, mesmo um de orientação feminista, terá dificuldades em construir um status honroso para aqueles definidos como não trabalhadores. No caso da Paridade do Cuidador, são oferecidas duas rotas para o alcance da igualdade de respeito, com os cidadãos-trabalhadores e os cidadãos-cuidadores, gozando de status equivalente. Contudo, remanescem as associações masculinidade-prover e feminilidade-cuidar e dificilmente na prática o trabalho assistencial alcançará verdadeira paridade com o de provisão - "é difícil imaginar como papéis de gênero 'separados mas iguais' poderiam proporcionar genuína igualdade de respeito hoje” (FRASER, 1997, p. 58).

A prevenção da marginalização, por sua vez, é apenas razoável num contexto de Provedor Universal. Com efeito, o modelo combate a marginalização sob uma faceta essencialmente trabaIhista, estreitando a noção de participação. Ao esperar ocupações de tempo integral para todos os capazes disso, pode efetivamente impedir a participação na política e na sociedade civil. A situação é mais grave no que tange à Paridade do Cuidador, pois, ao apoiar o cuidado informal realizado pelas mulheres, acaba por reforçar a ideia daquele trabalho como feminino e consolidar e divisão por gênero do trabalho doméstico. Ao institucionalizar mercados laborais duais, em acréscimo, o modelo marginaliza as mulheres dentro do setor de emprego. Pode também fazê-lo no que toca às esferas políticas e na sociedade civil, em razão da persistente associação entre cuidado e feminilidade.

No que concerne à eliminação do androcentrismo, por fim, o Modelo do Provedor Universal apresenta fraco desempenho. Ele valoriza justamente a esfera tradicionalmente associada aos homens - o emprego - para possibilitar que as mulheres nela se enquadrem. $\mathrm{O}$ cuidado tipicamente prestado pelas mulheres 
é pensado instrumentalmente: não possui valor social por si mesmo. O cidadão ideal-típico é o provedor, mas agora neutro em termos de gênero. No entanto, o conteúdo desse status é implicitamente masculino - corresponde à metade masculina do velho casal provedor/cuidador, mas agora exigido para todos, sem aproveitamento de nenhuma das virtudes ou capacidades distintivas da metade feminina, seja para as mulheres, seja para os homens. O Modelo da Paridade do Cuidador, a seu turno, é razoável no combate aos padrões androcêntricos atualmente reinantes. Afinal, trata o cuidado como intrinsecamente valioso, acomodando formas de vida tipicamente associadas à "feminilidade" e rejeitando a exigência de que as mulheres devam assimilar padrões "masculinos". Porém, não valoriza o cuidar a ponto de demandar também dos homens a participação em sua execução; nesse sentido, representa apenas metade de uma ofensiva de larga escala ao androcentrismo.

\section{CONCLUSÕES: RUMO AO MODELO DO CUIDADOR UNIVERSAL}

Pelo visto, aparentemente nenhuma das saídas feministas consegue alcançar a perseguida equidade de gênero. Não se trata aqui da dificuldade em concretizar as pré-condições impostas por ambos os modelos, tais como o significativo controle público sobre as corporações, a capacidade de direcionar investimentos para a criação de empregos permanentes de alta qualidade, a habilidade de tributar lucros e fortunas em taxas suficientes para financiar amplos programas sociais de elevada qualidade ou mesmo a obtenção de largo apoio popular para um welfare state compromissado com a equidade de gênero. Segundo Fraser (1994, p. 610), "se ambos os modelos são utópicos nesse sentido, nenhum deles é utópico o bastante", isto é, mesmo com as condições favoráveis não seriam capazes de efetivar a equidade desejada.

Com efeito, nenhum dos modelos promove a plena participação das mulheres em pé de igualdade com os homens na política e na sociedade civil; nenhum deles valoriza as práticas associadas à feminilidade a ponto de requerer que também os homens as desempenhem, ou seja, nenhum exige uma mudança dos homens. Considerando-se os benefícios de cada uma das opções, 


\section{temporolis}

a chave para atingir a equidade de gênero em um welfare state pós-industrial é fazer dos atuais padrões de vida das mulheres a norma para todos. As mulheres hoje frequentemente combinam prover (breadwinnig) e cuidar (caregiving), embora com grande dificuldade e constrangimento. Um welfare state pós-industrial deve assegurar que os homens façam o mesmo, ao tempo em que redesenha as instituições de forma a eliminar a dificuldade e o constrangimento. Poderíamos chamar esta visão de Cuidador Universal (FRASER, 1994, p. 611, grifo da autora).

A terceira opção para um novo cenário seria então "induzir os homens a se tornarem mais parecidos com o que as mulheres são agora" (FRASER, 1997, p. 60), "feminizando" as trajetórias vitais dos homens (ESPING-ANDERSEN, 2010). Algumas características desse welfare state pós-industrial poderiam ser então delineadas. De início, o setor do emprego não possuiria duas faixas/ trilhas, pois todas as ocupações seriam desenhadas para trabaIhadores que também são cuidadores, o que já significaria módulos semanais de jornada de trabalho mais curtos que os atuais. Todos contariam ainda com serviços que possibilitassem o acesso ao emprego, mas não sob a perspectiva de que os empregados deslocariam todo o cuidar para os serviços sociais. De fato, algum cuidado informal seria subsidiado publicamente e integrado no mesmo patamar do trabalho remunerado em um único sistema de seguridade social. Outra parcela do cuidar seria realizada nos lares por parentes e amigos, não necessariamente famílias nucleares heterossexuais. Ainda, uma parte da assistência subsidiada seria realizada completamente fora do ambiente doméstico, em instituições da sociedade civil financiadas pelo Estado e localmente organizadas, nas quais adultos sem filhos, idosos e outras pessoas sem responsabilidades semelhantes se uniriam a pais, parentes e outros em atividades assistenciais autogeridas e democráticas.

Assim, um Estado de bem-estar nos moldes do Cuidador Universal promoverá a equidade pelo desmantelamento da oposição por gênero entre prover e cuidar, integrando atividades atualmente separadas, eliminando sua codificação por gênero e 
encorajando os homens a realizarem-nas. Se a oposição supracitada é um dos pilares da atual ordem de gênero, isso representa uma reestruturação completa dessa instituição social. Na verdade, equivale a "subverter a divisão do trabalho por gênero existente e reduzir a importância do próprio gênero enquanto princípio estruturador da organização social. No limite, isso sugere desconstruir o gênero" (FRASER, 1997, p. 61). Ao desconstruir aquela oposição entre prover e cuidar, o modelo igualmente desmontaria a oposição correlata entre cenários público-institucionais burocráticos e privado-domésticos íntimos. Tratando a sociedade civil como um lócus adicional para o cuidado, escaparia ao mesmo tempo do "trabalhismo" do Provedor Universal e do "privatismo doméstico" da Paridade do Cuidador.

Logo, o Modelo do Cuidador Universal parece ser a melhor opção disponível para mitigar os potenciais conflitos entre as diversas (e complexas) exigências normativas da equidade de gênero, minimizando a necessidade de escolhas excludentes e transações insatisfatórias (trade-offs). Em suma, "realizar a equidade de gênero em um welfare state pós-industrial [...] requer desconstruir o gênero" (FRASER, 1997, p. 62). De fato, a proposta fraseriana parece adequada se não pretendemos recair num reducionismo economicista ou culturalista, uma vez que

mesmo as mais materiais instituições econômicas
possuem uma dimensão cultural constitutiva, ir-
redutível; elas estão permeadas de significações e
normas. De modo recíproco, mesmo as mais discur-
sivas práticas culturais possuem uma dimensão po-
lítico-econômica constitutiva, irredutível; elas estão
embasadas em apoios materiais. Então, longe de
ocuparem duas esferas impermeáveis separadas,
injustiça econômica e injustiça cultural estão usual-
mente interimbricadas de modo a reforçarem uma a
outra dialeticamente (FRASER, 1995, p. 72).

Nesse sentido, a estratégia de desconstrução do gênero (bem como das demais oposições - negro/branco; homo/hétero etc.) apresenta caráter transformador, pois intenta reparar a subordinação de status das mulheres pelo desmonte das oposições simbólicas que fundamentam os padrões institucionalizados 


\section{temporalis}

de valoração cultural, desestabilizando as diferenciações de status e alterando a autoidentidade de todos os atores sociais.

Por fim, o avanço num sentido utópico para o modelo de Cuidador Universal resgata como plenamente humana essa atividade individual e social responsável pela própria constituição da personalidade, o cuidado. Imaginar formas de vida em que o cuidado seja o epicentro social, a atividade privilegiada da trajetória vital humana, talvez se mostre uma das únicas maneiras disponíveis de inversão da agogia axiológica presente.

\section{REFERÊNCIAS}

ARRETCHE, Marta Teresa da Silva. Emergência e desenvolvimento do welfare state: teorias explicativas. Bib. Boletim Informativo e Bibliográfico de Ciências Sociais, n. 39, n. 1, p. 3-40, sem. 1995,

ESPING-ANDERSEN, Gosta. Social foundations of postindustrial economies. New York: Oxford University Press, 1999.

. Primera lección. Familia y revolución del papel de la mujer. In: ESPING-ANDERSEN, Gosta; PALIER, Bruno. Los tres grandes retos del Estado del bienestar. Tradução de Pau Joan Hernandéz. Barcelona: Planeta, 2010. p. 19-54.

FRASER, Nancy. After The Family Wage: Gender Equity and the Welfare State. Political Theory, n. 22, p. 591-618, nov. 1994.

. From Redistribution to Recognition? Dilemmas of Justice in a 'Postsocialist' Age. New Left Review, n. 1/212, p. 68-93, jul.-ago. 1995.

. After The Family Wage: a postindustrial thought experiment. In: FRASER, Nancy. Justice interruptus: critical reflections on the 'postsocialist' condition. New York: Routledge, 1997. p. 41-66.

. Recognition without Ethics? Theory, Culture \& Society, London, v. 18, n. 2-3, p. 21-42, 2001. 
FRASER, Nancy; HONNETH, Axel. Redistribution or recognition?: a political-philosophical exchange. Londres: Verso, 2003.

LIMA, Alex Myller Duarte. Justiça em Nancy Fraser. 2010. Dissertação (Mestrado em Ética e Epistemologia) - Universidade Federal do Piauí, Teresina, 2010.

NUSSBAUM, Martha. Women and Human Development. New York: Cambridge University Press, 2000.

PALIER, Bruno. Presentación. Un Estado del bienestar par alas envejecidas sociedades posindustriales. In: ESPING-ANDERSEN, Gosta; PALIER, Bruno. Los tres grandes retos del Estado del bienestar. Tradução de Pau Joan Hernandéz. Barcelona: Planeta, 2010. p. 7-18.

ROSA, Lúcia Cristina dos Santos. CAPS: um serviço de classe, gênero e etnias. 2014. Tese (Pós-doutorado em Saúde Coletiva) Universidade Estadual de Campinas, Campinas, 2014.

UNITED NATIONS ORGANIZATION. United Nations Development Programme. Human Development Report 2003: millennium development goals: a compact among nations to end human poverty. New York: Oxford University Press, 2003.

UNITED NATIONS ORGANIZATION. United Nations Development Programme. Human Development Report 2005: international cooperation at a crossroads: Aid, trade and security in an unequal world. New York: Hoechstetter Printing Co., 2005. 